\title{
Morbid Adherent Placenta: Morbidity and Mortality Report from a Developing Country
}

\author{
Nusrat Nisar, Saima Ghaffar, Farhat Jokhio
}

\begin{abstract}
OBJECTIVE: To determine the frequency of Morbidly Adherent Placenta (MAP) in pregnant women having history of obstetrical scar and its outcome in perspective of emergency or planned surgery. METHODOLOGY: This retrospective study was conducted in duration of one year from January to December 2016, in the Department of Obstetrics and Gynecology, Liaquat University of Medical and Health Sciences Jamshoro Sindh Pakistan. All the patients who were pregnant with history of previous scar diagnosed as a case of MAP were included while. Primigravida \& Placental abruption cases were excluded. Data was analyzed through SPSS Version 21. Mean \pm SD, frequencies \& percentages were calculated. Chi-square was used as test of significance.

RESULTS: Total 68 cases of MAP sorted out from the scrutiny of records of 10,000 cases. The mean \pm SD age of all patients was $28.14 \pm 4.57$ years ranging from 19 to 38 years. The mean \pm SD gestational age was $31.66 \pm 3.33$ weeks. Patients were divided in two groups one who presented in emergency and second group of women diagnosed during antenatal period. The most common types of MAP were Placenta Accrete 30 (44.11\%) and Placenta Percreta 29 (42.64\%). Incidence of maternal death, surgical \& post-operative complications, blood loss, and mean length of hospital stay were significantly less common among antenatal group. $(P$ value $=0.001)$.

CONCLUSION: Morbidly adherent placenta is relatively less common in our women. Placenta Accreta and Percreta were the frequent types.
\end{abstract}

KEY WORDS: Morbidly adherent placenta, Morbidity, Mortality, Developing country.

This article may be cited as: Nisar N, Ghaffar S, Jokhio F. Morbid Adherent Placenta: Morbidity and Mortality Report from a Developing Country. J Liaquat Uni Med Health Sci. 2020;19(02): 82-6. doi: 10.22442/jlumhs.201920667

\section{INTRODUCTION}

Morbidly adherent placenta (MAP) is an obstetrical condition of abnormal adherence and in separablility of placental villi either wholly or partially to the uterine wall instead of its normal site i-e; decidua basilis ${ }^{1}$. It usually leads to severe hemorrhage at the time of delivery resulting in high maternal morbidly and mortality ( $7 \%-10 \%$ cases), thus making it one of sever life threatening complications of pregnancy ${ }^{2,3}$. Until 1980 's its incidence was very low i-e; 1 in 70,000 births ${ }^{4}$. However; with the rise in the rate of cesarean delivery over past thirty years, the incidence of MAP has progressively increased throughout the world. Recent reports suggest the incidence of MAP varies between $1 / 210$ to $1 / 2500$ births in developed nations ${ }^{5,6}$. Simultaneously, the rates reported from low resource countries are also very high. In a recent study from Karachi, the MAP incidence recorded was $1.83 / 1000$ deliveries $^{7}$.

Several factors are associated with high incidence of MAP. The main risk factors are previous damage to the protective uterine decidua secondary to cesarean section, myomectomy, repeated uterine curettage ${ }^{8}$. MAP is associated with considerable maternal morbidity i-e; postpartum haemorrhage, disseminated intravascular coagulation, hysterectomy, bladder and ureteric trauma, acute respiratory distress syndrome and acute tubular necrosis. Blood loss after tried placental removal has been mentioned to be higher than $3000 \mathrm{ml}$ in $90 \%$ of cases, even when hysterectomy is performed, as many as $90 \%$ of patients require transfusion and $40 \%$ require $>10$ units of packed red blood cells. In a bad resource country, it results in high quotes of maternal morbidity and mortality ${ }^{9-11}$.

The optimal management of MAP is extremely challenging as most of these cases are diagnosed during labour or cesarean section. A standard care of MAP is planned cesarean hysterectomy with placenta in situ without any attempt of placental delivery. This may limit the extent of maternal morbidity and mortality. The conservative treatment options include methotrexate and if placenta is not possible to remove from uterine wall then second option is cesarean hysterectomy, ${ }^{10}$ which otherwise can lead to severe maternal consequences like haemorrhage, D\&C, hysterectomy, urinary bladder and ureteric trauma ${ }^{11}$. In Pakistan, obstetrical haemorrhage is one of the leading causes of maternal morbidity and mortality during parturition ${ }^{12}$. The women are often anaemic and report to hospital in emergency as unbooked 
cases. The rate of caesarean section, myomectomy \& hysterectomy are increasing in Pakistan like most other countries. Their long term maternal complications are rarely studied. One such severe complication is MAP. The present study was aimed to find out the frequency of MAP in the local population referred to a tertiary care hospital and to determine the outcome of woman in perspective of emergency or planned surgery in these cases of MAP.

\section{METHODOLOGY}

This retrospective cross-sectional study carried out with the help of medical audit over a period of one year from January to December 2016, in the Department of Obstetrics and Gynecology, Laiquat University Hospital Hyderabad / Jamshoro.

Pregnant patients with history of previous scar were included in the study. Primigravida and Placental abruption cases were excluded. All the patients who were diagnosed as a case of MAP were identified from the record books of labour ward, operating room and the ICU. The medical record sheets of all identified cases were reviewed. Demographic data like maternal age, gestational age, parity, residence, antenatal booking status and mode of admission was collected. Woman having $\geq 3$ antenatal visits were categorized as "booked cases". Previous history of caesarean deliveries and their number was noted.

Women reaching to emergency room without prior diagnosis of MAP followed by operation in emergency were labeled as emergency cases while those who were admitted through OPD with suspicion and/ or diagnosis of MAP and operated with schedule were labeled as planned cases. Comparison of the two modes was done in relation to other variables.

The surgical notes in particular placental localization, loss of blood, blood transfusion history, the surgical procedure and subsequent management to control hemorrhage was noted. The Intraoperative surgical complications like bladder or bowl injuries were recorded. Critical care assessment, hospital stay, postoperative complications like fever, DVT, wound infection, anemia and maternal outcome were recorded.

Three categories of MAP were defined clinically by operative reports. The exploration was made for term placenta accreta, placenta increta and placenta percreta.

Data was analyzed through SPSS Version 21. In the descriptive analysis, mean and standard deviation Mean \pm SD were expressed on continuous variables like age and parity, while proportions and percentages of categorical variables were calculated. Patients were compared in two groups viz; planned/ scheduled cases (diagnosed antenatal) versus emergency treatment cases (diagnosed intrapartum). The stratified analysis of maternal age, gestational age, parity \& reason for scar (previous surgery like $\mathrm{C} /$ Section, myomectomy, hysterotomy) was done with application of chi-square taking the $P$ value $\leq 0.05$ as significant.

\section{RESULTS}

There were total 68 cases of MAP sorted out from the scrutiny of records of 10,000 cases. This shows that the annual incidence of MAP was $0.68 \%$ in this center. The mean \pm SD age of all patients was $28.14 \pm 4.57$ years ranging from 19 to 38 years. The mean \pm SD gestational age was $31.66 \pm 3.33$ weeks ranging from 28 to 36 weeks. The number of children ranged from 01 to 05 with mean \pm SD parity of $2.22 \pm 1.06$. The mean $\pm S D$ duration of hospital stay was $8.07 \pm 5.28$ days and mean \pm SD duration of ICU stay was $1.23 \pm 0.78$ days (Table I).

When compared patients in two groups viz; antenatal (planned cases) and intrapartum (emergency case), it was found that most of patients had presented in emergency 57 (83.6\%) Figure I shows that more patients presenting on OPD basis (antenatal group) were of younger age than the emergency cases and this was also reflected from the mean age $\pm S D$ age difference Figure II. The most common type of MAP in all cases were Placenta Accreta 30 (44.11\%) and Placenta Percreta 29 (42.64\%). However; in emergency group the cases of placenta Percreta 27 $(47.4 \%)(P$ value $=0.131$; Table II) more frequent than other two types of MAP.

Table II compares the two groups and shows that only $1 / 3$ of cases in antenatal group were booked and in emergency group only $6(10 \%)$ were booked cases $(P$ value $=0.049$ ). All of antenatal group cases belonged to urban areas while in emergency mostly were referred from rural areas $(P$ value $=0.001)$. It was also significantly noted that none of women in antenatal group had $>2$ previous Lower Segment Cesarean Section (LSCS) while on the other hand $21.1 \%$ and $15.8 \%$ women in emergency group had history of 3 and $>3$ previous LSCS respectively ( $P$ value $=$ 0.005). (Table II)

It was noted that in antenatal (planned cases) group mean blood loss was less compared to emergency group $(2.2 \pm 0.3$ versus $2.7 \pm 0.7 ; P$ value $=0.001)$. Simultaneously, the average need of blood products (RBC, FFP) and mean length of hospital stay was lower among antenatal group. (Table III) Further; incidence of maternal death, surgical and post-operative complications (wound infection, renal failure and anemia) were much more common among intrapartum (emergency cases). (Table III) 
Nusrat Nisar, Saima Ghaffar, Farhat Jokhio

TABLE I: BASIC DESCRIPTIVE STATISTICS OF ALL MAP PATIENTS

\begin{tabular}{lcccc}
\hline \multicolumn{1}{c}{ Characteristic } & Minimum & Maximum & Mean & Std. Deviation \\
\hline Age of patient & 19 & 38 & 28.14 & 4.57 \\
\hline Parity & 01 & 05 & 2.22 & 1.06 \\
\hline Gestational age in weeks & 23 & 36 & 31.66 & 8.07 \\
\hline Duration of hospital stay (Days) & 01 & 18 & 1.23 & 5.28 \\
\hline Duration in ICU stay (Days) & 01 & 04 & 0.78 \\
\hline
\end{tabular}

\section{FIGURE I: AGE WISE COMPARISON OF MAP}

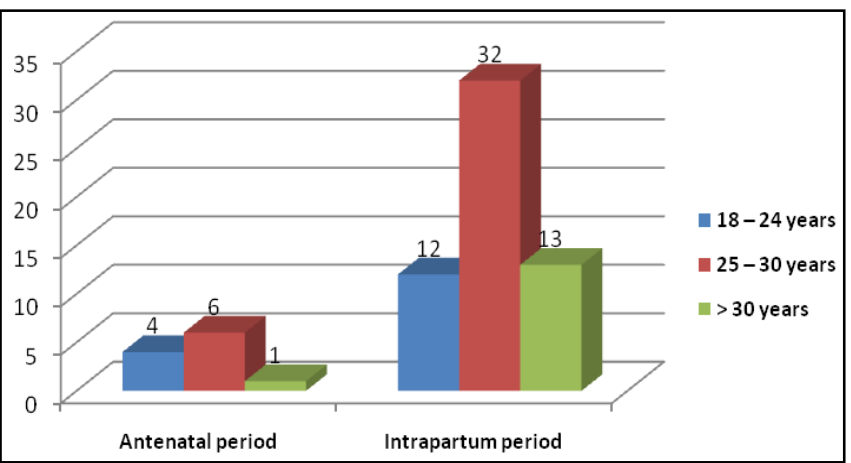

TABLE II: COMPARISON OF REPRODUCTIVE RISK FACTORS FOR MAP IN ANTENATAL AND IN TRAPARTUM PERIOD

\begin{tabular}{|c|c|c|c|}
\hline Variables & $\begin{array}{l}\text { Antenatal } \\
\text { period } \\
\text { (Planned } \\
\text { cases) } \\
\mathrm{n}(\%)\end{array}$ & $\begin{array}{l}\text { Intrapartum } \\
\text { period } \\
\text { (Emergency } \\
\text { cases) } \\
\mathrm{n}(\%)\end{array}$ & $P$ value \\
\hline Age (years $\pm S D$ ) & $26.0 \pm 4.2$ & $28.6 \pm 5.0$ & 0.111 \\
\hline $\begin{array}{l}\text { Gestational age } \\
\text { (weeks } \pm \text { SD) }\end{array}$ & $31.7 \pm 4.1$ & $31.5 \pm 3.6$ & 0.880 \\
\hline Parity \pm SD & $1.9(0.3)$ & $2.4(1.1)$ & 0.012 \\
\hline $\begin{array}{l}\text { Parity groups } \\
\text { One } \\
\text { Two } \\
>\text { Two }\end{array}$ & $\begin{array}{c}1(9.1) \\
10(90.9) \\
0(0)\end{array}$ & $\begin{array}{l}14(24.6) \\
21(36.8) \\
22(38.6)\end{array}$ & 0.002 \\
\hline $\begin{array}{l}\text { Booking status } \\
\text { Un-booked } \\
\text { Booked } \\
\end{array}$ & $\begin{array}{l}7(63.6) \\
4(36.4)\end{array}$ & $\begin{array}{c}51(89.5) \\
6(10.5) \\
\end{array}$ & 0.049 \\
\hline $\begin{array}{l}\text { Place of residence } \\
\text { Urban } \\
\text { Rural }\end{array}$ & $\begin{array}{c}11(100.0) \\
0(0)\end{array}$ & $\begin{array}{c}7(12.3) \\
50(87.7)\end{array}$ & $<0.001$ \\
\hline $\begin{array}{l}\text { Number of } \\
\text { previous LSCS } \\
\text { One } \\
\text { Two } \\
\text { Three } \\
\text { More than Three }\end{array}$ & $\begin{array}{c}1(9.1) \\
10(90.9) \\
0(0) \\
0(0)\end{array}$ & $\begin{array}{l}18(31.6) \\
18(31.6) \\
12(21.1) \\
9(15.8)\end{array}$ & 0.005 \\
\hline $\begin{array}{l}\text { Clinical diagnosis } \\
\text { at delivery } \\
\text { Placenta Accreta } \\
\text { Placenta Increta } \\
\text { Placenta Percreta }\end{array}$ & $\begin{array}{c}8(72.7) \\
1(9.1) \\
2(18.2)\end{array}$ & $\begin{array}{l}22(38.6) \\
8(14.0) \\
27(47.4)\end{array}$ & 0.133 \\
\hline
\end{tabular}

$S D$, standard deviation
FIGURE II: CLINICAL DIAGNOSIS OF TYPES OF MAP

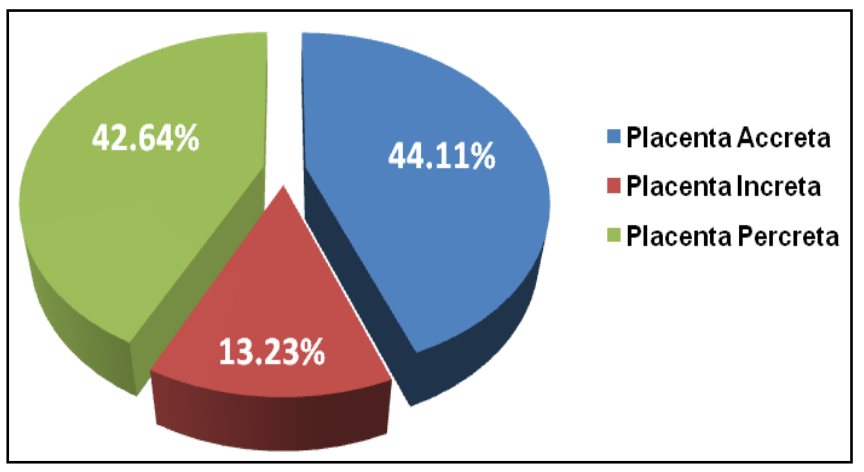

TABLE III: COMPARISON OF COMPLICATIONS DURING ANTENATAL AND INTRAPARTUM PERIOD IN WOMEN WITH MAP

\begin{tabular}{|c|c|c|c|}
\hline Factors & $\begin{array}{c}\text { Antenatal } \\
\text { period } \\
\text { (Planned } \\
\text { cases) } \\
\mathrm{n}(\%)\end{array}$ & $\begin{array}{l}\text { Intrapartum } \\
\text { period } \\
\text { (Emergency } \\
\text { cases) } \\
\mathrm{n}(\%)\end{array}$ & $P$ value \\
\hline $\begin{array}{l}\text { Average blood loss } \\
\text { (Mean } \pm \text { SD liters) }\end{array}$ & $2.2 \pm 0.3$ & $2.7 \pm 0.7$ & 0.001 \\
\hline \multicolumn{4}{|c|}{ Average blood products (mean $\pm S D$ ) } \\
\hline RBC & $3.3 \pm 0.5$ & $3.8 \pm 0.9$ & 0.069 \\
\hline FFP & $4.0 \pm 1.1$ & $3.9 \pm 1.0$ & 0.870 \\
\hline ICU transfer & $5(45.5 \%)$ & $25(43.9 \%)$ & 0.589 \\
\hline $\begin{array}{l}\text { Length of hospital } \\
\text { stay in days } \\
\text { (mean } \pm S D)\end{array}$ & $6.8 \pm 3.7$ & $8.4 \pm 5.4$ & 0.244 \\
\hline Maternal death & $2(18.2 \%)$ & $15(26.3 \%)$ & 0.443 \\
\hline \multicolumn{4}{|c|}{ Surgical complications $(n=16)$} \\
\hline Urinary tract injury & $1(100.0 \%)$ & $10(66.7 \%)$ & \multirow{3}{*}{ NA } \\
\hline Haemoatoma & $0(0 \%)$ & $1(6.7 \%)$ & \\
\hline Relaparotomy & $0(0 \%)$ & $4(26.7 \%)$ & \\
\hline \multicolumn{4}{|c|}{ Post-operative complications } \\
\hline Fever & $1(9.1 \%)$ & $5(8.8 \%)$ & \multirow{4}{*}{ NA } \\
\hline Wound infection & $1(9.1 \%)$ & $6(10.5 \%)$ & \\
\hline Renal failure & - & $2(3.5 \%)$ & \\
\hline Anemia & - & $6(10.5 \%)$ & \\
\hline
\end{tabular}




\section{DISCUSSION}

The current study was conducted to measure the magnitude of burden of morbidly adherent placenta and its outcome after emergency or planned surgery. The results show that case rate of MAP was $0.68 \%$ among all admitted pregnancies. Although the rate is not high in this population, yet the condition ended up with higher rates of maternal morbidity and mortality. Maternal deaths were $18.2 \%$ and $26.3 \%$ among planned and emergency cases of MAP. Overall rate of MAP documented ranges from $<1 \%$ to $2.45 \%$ in different regions of the world ${ }^{13,4-7}$.

An Irish study reported a doubling of rate of MAP in previous caesarean section population ${ }^{14}$. This MAP rate is not very high in this population.

The most common type of MAP overall and in antenatal cases in this study was placenta accreta which was $44.11 \%$, however emergency cases had more cases of placenta percreta (47.4\%). According to other studies; the frequency of placenta accreta was up to $75 \%$, placenta increta $17 \%$ \& that of placenta percreta was reported up to $7 \%{ }^{15,16}$. Former literature was more apparent for placenta percreta as far as clinical diagnosis is concerned $(P$ value = $0.013)^{17-20}$. Having scar of myomectomy or hysterotomy had more affinity for all three types of MAP. Wu S and coworkers ${ }^{21}$ has reported that $9.8 \%$ women who had the history of previous scar in the uterus had suffered from MAP. In the current study, we include only cases having history of scar due LSCS.

In the current study, overall mean age of patients was approximately 28 years. Majority of patients were of age range from 25-30 years in antenatal/ planned treatment group and Intra-partum/ emergency treatment group both. More of the younger age patients had presented in antenatal period while there were more elder age patients in emergency treatment group. With the increasing age, the frequency of Placenta acreta increases while there is rise followed by decrease in the rates of placenta increta and placenta percreta. The likely reason is that aging makes the uterus more flexible and lax which may lead to occurrence placenta accrete. Further elder age women are more likely to be more parous then the younger age women. This fact was also visualized from another finding that women having 1-2 children had low incidence of Placenta acreta and Placenta Percreta.

The antenatal group bled less, needed less blood infusion, had short hospital/ ICU stay and there were fewer surgical/ post-op complications in them. Other studies have also documented the similar picture whereby planned cases of MAP and those diagnosed in antenatal period were managed more favorably and had better outcomes than the emergency presenters. As gestational age increases, individuals with MAP have an increased risk of emergency bleeding.
However; in the current study, there was not any significant difference of gestational age among the emergency and planned cases $(P$ value $=0.880)$. It is a common finding that women with MAP start bleeding before 37 weeks and urgently need preterm delivery. This study found similar trend as mean gestational age at delivery in all cases was 31.66 weeks.

Rural women as noted in this study are usually prone to MAP and its complication and the reason to this is that they may not recall any intervention in past like myomectomy or D\&C. Therefore; screening should be focused to identify suspected MAP among rural women. Finally; this study recommends screening of all pregnant women through Doppler U/S for MAP in order to prevent the maternal \& neonatal morbidity and mortality.

There were certain limitations in this study. It was retrospective study with secondary data analysis. The results do not represent the entire population. Further; the outcome of pregnancy was not assessed in this study. Site and size of scar was also not measured which could have come up with more variability of presentations. Yet, the study with all its limitations has highlighted very important aspect of pregnant women who present with scar in uterus. We thus recommend that in future prospective studies with larger samples should be conducted to understand the dynamics of MAP in details.

\section{CONCLUSION}

Morbidly adherent placenta is relatively less common condition in our population. Placenta Accreta and Percreta are the frequent types of MAP. Middle age women are more affected. Antenatal diagnosis and planned case management leads to lesser maternal morbidity and mortality compared to intra-partum diagnosis and emergency management. Unbooked case, higher parity, $>2$ previous CS and rural cases present mostly in emergency. Early recognition of MAP by taking thorough history, US Doppler should be key focus of antenatal care among all women.

Ethical permission: LUMHS Departmental IRB No. Doc \# /OBGYN III/17-132, Dated: 17-11-2017.

Conflict of Interest: There is no conflict of interest.

Funding: There was no any funding agency.

\section{REFERENCES}

1. Tantbirojn $P$, Crum $C P$, Parast $M M$. Pathophysiology of placenta accreta: The role of decidua and extravillous trophoblast. Placenta. 2008; 29(7): 639-45.

2. Aggarwal R, Suneja A, Vaid NB, Yadav P, Sharma A, Mishra K. Morbidly adherent placenta: a critical review J Obstet Gynecol India. 2012; 62 (1): 57-61.

3. Wadhwa L, Gupta S, Gupta P, Satija B, Khanna R. Morbidly adherent placenta (MAP): lessons 
learnt. Open J Obsts Gynae. 2013; 3(01): 217-21. doi:10.4236/ojog.2013.31A040.

4. Cheng KK, Lee MM. Rising incidence of morbidly adherent placenta and its association with previous caesarean section: a 15-year analysis in a tertiary hospital in Hong Kong. Hong Kong Med J. 2015; 21(6): 511-7.

5. Khong TY. The pathology of placenta accreta, a worldwide epidemic. J Clin Pathol. 2008; 61(12): 1243-6.

6. Fitzpatrick KE, Sellers S, Spark P, Kurinczuk JJ, Brocklehurst $P$, Knight $M$. Incidence and risk factors for placenta accreta/increta/percreta in the UK: a national case-control study. PLoS One 2012; 7(12): e52893.

7. Ansar A, Malik T, Shuja S, Khan S. Hysterectomy as a management option for morbidly adherent placenta. J Coll Physicians Surg Pak. 2014; 24(5): 318-22.

8. Osser OV, Jokubkiene L, Valentin L. High prevalence of defects in cesarean section scars at transvaginal ultrasound examination. Ultrasound Obstet Gynecol. 2009; 34(1): 90-7.

9. Nageotte MP. Always be vigilant for placenta accreta. Am J Obstet Gynecol 2014; 211(2): 87-8.

10. Herath R, Wijesinghe PS. Management of morbidly adherent placenta. Srilanka J Obstet Gynecol. 2011; 33(2): 39-44.

11. Hayashi M, Nakai A, Satoh S, Matsuda $Y$. Adverse obstetric and perinatal outcomes of singleton pregnancies may be related to maternal factors associated with infertility rather than the type of assisted reproductive technology procedure used. Fertil Steril 2012; 98(4): 922-8.

12. Organization WH. The World Health Report 2005 - make every mother and child count: WHO. Geneva, Switzerland. 2005. Available from: https://www.who.int/whr/2005/ whr2005.
13. Edhi MM, Aslam HM, Naqvi Z, Hashmi $H$. Post-partum hemorrhage: causes and management. BMC Res Notes. 2013; 6: 236.

14. Begum S, Un-Nisa A, Begum I. Analysis of maternal mortality in a tertiary care hospital to determine causes and preventable factors. J Ayub Med Coll Abbottabad. 2003; 15(2): 49-52.

15. Higgins MF, Monteith C, Foley M, O'Herlihy C. Real increasing incidence of hysterectomy for placenta accreta following previous caesarean section. Eur J Obstet Gynecol Reprod Biol. 2013; 171(1): 54-6.

16. Kashani E, Azarhoush R. Peripartum hysterectomy for primary postpartum hemorrhage: 10 years evaluation. Euro J Exper Biol. 2012; 2 (1): 32-6.

17. Cieminski A, Dlugolecki F. Relationship between placenta praevia and maternal age, parity and prior caesarean deliveries. Ginekol Pol. 2005; 76 (4): 284-9.

18. Rulisa S, Umuziranenge I, Small $M$, van Roosmalen J. Maternal near miss and mortality in a tertiary care hospital in Rwanda. BMC Pregnancy Childbirth. 2015; 15: 203.

19. Alchalabi H, Lataifeh I, Obeidat B, Zayed F, Khader YS, Obeidat N. Morbidly adherent placenta praevia in current practice: prediction and maternal morbidity in a series of 23 women who underwent hysterectomy. J Matern Fetal Neonatal Med. 2014; 27(17): 1734-7.

20. Tikkanen $M$, Paavonen J, Loukovaara $M$, Stefanovic V. Antenatal diagnosis of placenta accreta leads to reduced blood loss. Acta Obstet Gynecol Scand. 2011; 90(10): 1140-6.

21. Wu S, Kocherginsky M, Hibbard JU. Abnormal placentation: Twenty-year analysis. Am J Obstet Gynecol. 2005; 192(5): 1458-61.

\begin{tabular}{|l} 
AUTHOR AFFILIATION: \\
Dr. Nusrat Nisar (Corresponding Author) \\
Associate Professor \\
Department of OBS \& GYNE \\
Liaquat University of Medical Health Sciences \\
(LUMHS), Jamshoro, Sindh-Pakistan. \\
Email:nushopk2001@hotmail.com \\
Dr. Saima Ghaffar \\
Senior Registrar \\
Department of OBS \& GYNE \\
LUMHS, Jamshoro, Sindh-Pakistan. \\
Dr. Farhat Jokhio \\
Assistant Professor \\
Department of Psychology \\
University of Sindh Jamshoro, Sindh-Pakistan.
\end{tabular}

